\title{
Two-dimensional (2D) numerical modelling of rainfall induced overland flow, infiltration and soil erosion: comparison with laboratory rainfall-runoff simulations on a two-directional slope soil flume
}

\author{
João R.C.B. Abrantes ${ }^{1,2,3 *}$, Nuno E. Simões ${ }^{1,4}$, João L.M.P. de Lima ${ }^{1,2}$, Abelardo A.A. Montenegro ${ }^{5}$ \\ ${ }^{1}$ Department of Civil Engineering, Faculty of Sciences and Technology, University of Coimbra, Rua Luís Reis Santos, Pólo II - Univer- \\ sidade de Coimbra, 3030-788 Coimbra, Portugal. \\ ${ }^{2}$ MARE UCoimbra - Marine and Environmental Sciences Centre, University of Coimbra, Rua da Matemática 49, 3004-517 Coimbra, \\ Portugal. \\ ${ }^{3}$ Itecons - Institute of Research and Technological Development in Construction, Energy, Environment and Sustainability, Rua Pedro \\ Hispano, 3030-289 Coimbra, Portugal. \\ ${ }^{4}$ INESC Coimbra - Institute for Systems Engineering and Computers at Coimbra, Rua Sílvio Lima, Pólo II - Universidade de Coimbra, \\ 3030-290 Coimbra, Portugal. \\ ${ }^{5}$ Department of Rural Technology, Rural Federal University of Pernambuco, Rua Dom Manoel de Medeiros s/n, Dois Irmãos, 50910-130 \\ Recife, PE, Brazil. \\ *Corresponding author. Tel.: +351915051391. E-mail: jrcbrito@msn.com
}

\begin{abstract}
This paper presents a two-dimensional (2D) numerical model of soil erosion and sediment transport resulting from rainfall induced overland flow. It is a spatial and temporal dynamic model combining physical and empirical laws and comprises: i) An overland flow module that solves the two-dimensional unsteady water flow equations on an infiltrating surface; ii) A soil infiltration module that uses a combined Horton-SCS scheme; and iii) A soil erosion and sediment transport module that solves the two-dimensional sediment transport equation, distinguishing between rill erosion, interrill erosion and sediment deposition.

The performance of the model was evaluated by comparing its results with observed data from laboratory rainfallrunoff experiments on a two-directional $2.00 \times 2.00 \mathrm{~m}^{2}$ soil flume set at $1 \%$ and $10 \%$ slopes in the $\mathrm{x}$ - and y-directions, respectively. The x-direction produced remarkably lower runoff and transported sediments than the y-direction. The numerical model significantly underestimated x-direction lower values of runoff and transported sediments. However, in the y-direction the model presented very good performance. Overall, in total terms (x-plus y-direction), the numerically simulated graphs of runoff and sediment transport were in very good agreement with corresponding experimental measurements, demonstrating the laboratory proof-of-concept of the model.
\end{abstract}

Keywords: Two-dimensional modelling; Overland flow; Soil erosion; Horton-SCS infiltration; Two-directional laboratory soil flume; Rainfall simulation.

\section{INTRODUCTION}

Soil erosion has been widely recognized as a serious environmental degradation problem throughout the history (Montgomery, 2007). It can reduce soil fertility and productivity (Boardman et al., 2009) and increase the transport of sediment and pollutants to freshwater bodies (Rickson, 2014). Accurate prediction of soil erosion is therefore essential in land and water management (Panagos and Katsoyiannis, 2019).

Mathematical models are cost-effective tools for improving our understanding of erosion processes and predict its effects on soil and water quality (Panagos and Katsoyiannis, 2019). A robust mathematical model can provide a cost-effective tool by which many scenarios can be simulated and compared in order to find the best alternative of addressing a particular problem (Batista et al., 2019; Singh and Woolhiser, 2002). Consequently, a wide spectrum of soil erosion models, ranging from simple empirical formulas, such as the Universal Soil Loss Equation (USLE, Wischmeier and Smith, 1978) or its revised version (RUSLE, Renard et al., 1997), to comprehensive physically based distributed descriptions, such as the KINematic runoff and EROSion (KINEROS, Woolhiser et al., 1990), the Water Erosion Prediction Project (WEPP, Flanagan and Nearing,
1995), or the EUROpean Soil Erosion Model (EUROSEM, Morgan et al., 1998), have been proposed for the prediction of soil erosion and sediment transport (Batista et al., 2019; Singh and Woolhiser, 2002).

Physically based models are generally the most scientifically robust and flexible models and provide an understanding of the fundamental and non-stationary processes involved in the detachment, transport and deposition of sediments and provide an access to their spatial and temporal variation (Nearing, 2000). However, due to the complexity of such processes, fully physically based models have not yet become a practical tool (Stroosnijder, 2005). Their parametrisation is complex, and they are data intensive. Also, such data always carry a level of uncertainty, are expensive and time consuming and, therefore, most of the times the amount of data needed is not readily available (Stroosnijder, 2005).

Reduced-scale laboratory experiments using soil flumes and rainfall simulators allow observing the fundamental mechanisms in the complex hydrologic processes (i.e. overland flow generation, infiltration, erosion) under controlled conditions (Abrantes et al., 2018; de Lima et al., 2013, 2019; Montenegro et al., 2013; Prats et al., 2017). They allow to investigate effect of specific factors such as slope geometry, soil conditions and 
rainfall characteristics and allow for a quicker and easier way to access good-quality data, such as peak discharges, sediment concentrations and time to peaks. The availability of such goodquality data provides a good chance to evaluate the performance of numerical models and improve them (Abrantes et al., 2015, 2019; Cuomo et al., 2016; Deng et al., 2005; Isidoro and de Lima, 2013; Silveira et al., 2016; Singh and de Lima, 2018).

This paper presents a two-dimensional (2D) numerical model of soil erosion and sediment transport resulting from rainfall induced overland flow. The main objective of this study is to present a proof of concept of the model performance in simulating soil erosion and sediment transport produced by single rainfall events in a two-directional (i.e. slope in $\mathrm{x}$ - and $\mathrm{y}-$ directions) laboratory soil flume on a steady flat surface. It is expected that, even on a flat soil surface, a two-dimensional model will perform better than a one-dimensional model in the case of two-directional flow and spatially distributed rainfall. The performance of the model was evaluated for the $\mathrm{x}$ - and $\mathrm{y}$ directions individually. To the best of our knowledge, the essential novelty of this study resides in the originality of the numerical model that couples three specific modules, combining physical and empirical laws, and in the originality of the soil flume experiments that allows to evaluate surface runoff in $\mathrm{x}$ - and $\mathrm{y}$-directions individually.

\section{GOVERNING EQUATIONS}

The model is a spatial and temporal dynamic model combining physical and empirical laws and comprises three main modules: i) An overland flow module that solves the twodimensional unsteady water flow equations on an infiltrating surface; ii) A soil infiltration module that uses a modified version of the empirical Horton's infiltration equation; and iii) A soil erosion and sediment transport module that solves the twodimensional sediment transport equation.

\section{Overland flow and soil erosion}

Overland flow was described by the two-dimensional shallow-flow equations commonly referred to as the Saint-Venant equations, which include the equation of continuity and two equations of motion for the coordinate directions $x$ and $y$ (Zhang and Cundy, 1989):

$$
\begin{aligned}
& \frac{\partial h}{\partial t}+\frac{\partial v_{x} h}{\partial x}+\frac{\partial v_{y} h}{\partial y}=p-i \\
& \frac{\partial v_{x} h}{\partial t}+\frac{\partial}{\partial x}\left(v_{x}{ }^{2} h+\frac{1}{2} g h^{2}\right)+\frac{\partial v_{x} v_{y} h}{\partial y}=g h\left(-\frac{\partial Z}{\partial x}-S_{f x}\right) \\
& \frac{\partial v_{y} h}{\partial t}+\frac{\partial v_{x} v_{y} h}{\partial x}+\frac{\partial}{\partial y}\left(v_{y}{ }^{2} h+\frac{1}{2} g h^{2}\right)=g h\left(-\frac{\partial Z}{\partial y}-S_{f y}\right)
\end{aligned}
$$

where $h$ is the water depth, $v_{x}$ and $v_{y}$ are the depth-averaged flow velocity components in the $x$ and $y$ directions, respectively, $p$ is the rainfall intensity, $i$ is the infiltration rate, $g$ the gravitational constant, $Z$ is the bed elevation, $t$ is the time and $S_{f x}$ and $S_{f y}$ are the friction slopes in the $x$ and $y$ directions, respectively and were approximated by the Manning's formula and expressed in terms of conservation variables, as:

$$
S_{f x}=\frac{n^{2} v_{x}\left(v_{x}{ }^{2}+v_{y}{ }^{2}\right)^{1 / 2}}{h^{4 / 3}}, \quad S_{f y}=\frac{n^{2} v_{y}\left(v_{x}{ }^{2}+v_{y}{ }^{2}\right)^{1 / 2}}{h^{4 / 3}}
$$

where $n$ is the Manning's roughness coefficient. Assumptions and derivation of Eqs. (1-3) can be found in detail in Zhang and Cundy (1989).

Equations used for soil erosion and sediment transport resulting from rainfall induced overland flow vary significantly due to different understanding and treatments of the sediment detachment, transport and deposition mechanisms (Flanagan and Nearing, 1995; Morgan et al., 1998; Woolhiser et al., 1990). Raindrop impact and/or overland flow can detach sediments from the soil surface. A critical force needs to be exerted by either a raindrop or a flow before detachment occur. Transport of detached material can occur as the result of raindrops and flow acting singly or together. Sediment deposition occurs when the flow can no longer support the suspended sediments, usually as result of a decrease in the flow transport capacity (Kinnell, 2005).

According to these principles, soil erosion was divided into three main mechanisms: i) Interrill erosion, that reflects the detachment and transport of sediments by the action of raindrops; ii) Rill erosion, that reflects the detachment and transport of sediments by the action of overland flow; and iii) Sediment deposition, that reflects the settling down of sediments. These mechanisms were described by the following two-dimensional sediment transport equation:

$$
\frac{\partial h c}{\partial t}+\frac{\partial v_{x} h c}{\partial x}+\frac{\partial v_{y} h c}{\partial y}=e_{i}+e_{r}-d
$$

where $c$ is the overland flow mass sediment concentration and $e_{i}$ and $e_{r}$ are the volumetric interrill and rill erosion, respectively, and $d$ is the sediment deposition.

The right side of Eq. (5) represents the constant exchange of sediment particles in the vertical between the soil surface and the flow, and its terms can be expressed as follows (Cao et al., 2002; Deng et al., 2008):

$$
e_{i}=\rho_{s} \frac{p^{2}}{\omega_{s}} \exp ^{(-\eta h)}
$$

$e_{r}=\left\{\begin{array}{ccc}\rho_{s} \xi\left(\theta-\theta_{c}\right) \frac{1}{h d_{s}^{2 / 10}} \sqrt{v_{x}^{2}+v_{y}^{2}} & \text { if } \theta>\theta_{c} \\ 0 & \text { if } \theta \leq \theta_{c}\end{array}\right.$

$d=\rho_{s} \omega_{s} \alpha c(1-\alpha c)^{2}$

where $d_{s}$ is the mean sediment particle diameter, $\theta_{c}$ is the dimensionless critical Shields parameter for initiation of sediment movement and $\theta$ is the dimensionless flow shear stress and can be expressed as (Liu and Beljadid, 2017):

$$
\theta=\frac{n^{2}}{\left(\rho_{s} / \rho-1\right) d_{s} h^{1 / 3}}\left(v_{x}^{2}+v_{y}{ }^{2}\right)
$$

where $\rho$ and $\rho_{s}$ are the density of clear water and sediment particles, respectively. $\omega_{s}$ is the settling velocity of a single sediment particle in tranquil water (Cheng, 1997): 


$$
\omega_{s}=\sqrt{\left(13.95 \frac{v}{d_{s}}\right)^{2}+1.09 g d_{s}\left(\frac{\rho_{s}}{\rho}-1\right)}-13.95 \frac{v}{d_{s}}
$$

where $v$ is the kinematic viscosity of water.

$\eta, \xi$ and $\alpha$ are calibration parameters to control interrill erosion, rill erosion and sediment deposition, respectively. $\eta$ represents the damping rate due to the water depth, $\xi$ controls the erosion force of the of the overland flow and $\alpha$ describes the difference between the bed surface sediment concentration and the overland flow sediment concentration and can be approximated as:

$$
\alpha=\min \left(2, \frac{1-p_{s}}{c}\right)
$$

where $p_{s}$ is the soil porosity.

The numerical methods used to solve the governing equations and to address the initial and boundary conditions are presented in "APPENDIX A". The governing equations (Eqs. (1-3) and (5)) were solved using the explicit finite-difference method based on the MacCormack operator-splitting scheme. In addition, specific numerical procedures were developed to handle the wet/dry front, in such a way that numerical simulations can start on an initially dry surface, allowing a more realistic prediction of the interaction between rainfall, infiltration and overland flow.

\section{Infiltration}

Infiltration was computed using a modified version of the Horton's infiltration equation (Horton, 1933) with a calibration methodology of its parameters based on formal analogies with the SCS-CN method (USDA, 2004). The result was presented in Gabellani et al. (2008) and is a general relation between SCS-CN and modified parameters of Horton's method.

Horton (1933) proposed an exponential decay equation to describe the variation in time of the infiltration capacity of the soil during a rainfall event as:

$$
f(t)=f_{\infty}+\left(f_{0}-f_{\infty}\right) e^{-k t}
$$

where $f(t)$ is the infiltration rate at time $\mathrm{t}$ from the beginning of the rainfall event, $f_{\infty}$ and $f_{0}$ are the final (minimum) and initial (maximum) infiltration rates, respectively, and $k$ is the exponential time decay coefficient.

The main restrictions to the application of Horton's equation in its original form are the difficulty of considering rainfall with intensities lower than $f_{0}$, the impossibility to describe the effect of dry periods inside the rainfall event, and the difficulty of obtaining reliable estimates for its parameters. This modified version of the Horton's infiltration accounts for a relation between the infiltration capacity and soil moisture conditions for a more successful parameter calibration and accounts for intermittent and low-intensity rainfall events, namely lower than $f_{0}$.

According to this methodology, the upper soil layer is modelled as a linear reservoir with a water volume $V(t)$ varying in time between 0 for dry soil condition and $V_{\max }$ for saturated soil condition. $V(t)$ varies with the infiltration in the upper soil layer $i(t)$ and the percolation to deeper soil layers $i_{p}(t)$, according to the following mass-balance equation:

$$
\frac{\partial V}{\partial t}=i(t)-i_{p}(t)
$$

$i(t)$ is simultaneously regulated by the rainfall intensity $p(t)$ and the infiltration capacity $f(t)$, as follows:

$i(t)=\left\{\begin{array}{lll}p(t) & \text { if } & p(t) \leq f(t) \\ f(t) & \text { if } & p(t)>f(t)\end{array}\right.$

Both $f(t)$ and $i_{p}(t)$ vary linearly with $V(t)$, as follows:

$f(t)=f_{0}-\left(f_{0}-f_{\infty}\right) \frac{V(t)}{V_{\max }}$

$i_{p}(t)=f_{\infty} \frac{V(t)}{V_{\max }}$

For dry soil condition, i.e. $V(t)=0, f(t)$ and $i_{p}(t)$ assume the values of $f_{0}$ and 0 , respectively. For saturated soil condition, i.e. $V(t)=V_{\max }$, both are equal to $f_{\infty}$.

Substituting Eqs. (14-16) in Eq. (13) and integrating it in $\Delta t$, results in:

$$
\begin{aligned}
& V\left(t_{i+1}\right)= \\
& \left\{\begin{array}{c}
\frac{p\left(t_{i}\right) V_{\max }}{f_{\infty}}+e^{-\frac{f_{\infty}}{V_{\max }} \Delta t}\left(V\left(t_{i}\right)-\frac{p\left(t_{i}\right) V_{\max }}{f_{\infty}}\right) \text { if } p\left(t_{i}\right) \leq f\left(t_{i}\right) \\
V_{\max }\left(1-e^{-\frac{f_{0}}{V_{\max }} \Delta t}\right)+V\left(t_{i}\right) e^{-\frac{f_{0}}{V_{\max }} \Delta t} \text { if } p\left(t_{i}\right)>f\left(t_{i}\right)
\end{array}\right.
\end{aligned}
$$

where $V\left(t_{i+1}\right)$ is $V(t)$ at $t=t_{i+1}$ and $p\left(t_{i}\right)$ and $f\left(t_{i}\right)$ are the values of $p(t)$ and $f(t)$ at $t=t_{i}$ and are assumed to be constant between $t_{i}$ and $t_{i+1}$.

The calibration of the parameters $f_{0}, f_{\infty}$ and $V_{\max }$ was performed based on an analytical derivation of the Horton's equation and combination with the SCS-CN method (USDA, 2004), resulting in:

$$
\begin{aligned}
& f_{0}=-\frac{V_{\text {max }}}{0.8 T_{P}} \ln \frac{V_{\text {max }}}{P+0.8 V_{\text {max }}} \\
& f_{\infty}=c_{f} f_{0}
\end{aligned}
$$

where $T_{P}$ is the duration of the rainfall event, $P$ is the cumulated rainfall of the event and $c_{f}$ is a calibration parameter varying from 0 to 1 . $V_{\max }$ can be compared the maximum retention capacity $(S)$ of the SCS-CN method, calculated as:

$$
V_{\max }=S=25.4\left(\frac{1000}{C N}-10\right)
$$

where $C N$ is the dimensionless curve number parameter.

It should be noted that this methodology is only valid from the moment that the cumulative rainfall $(P)$ exceeds the initial abstraction $I a$, i.e. $P>I a=0.2 S$. Till that moment, all rainfall is considered to infiltrate into the upper soil layer, therefore becoming water input to the water reservoir, i.e. $V(t)$.

\section{METHODOLOGY Experimental tests}

To evaluate the proposed two-dimensional numerical model, data from laboratory rainfall-runoff experiments on a twodirectional free-drainage square soil flume were used. The experiments were performed on the laboratory setup schematised 
a)

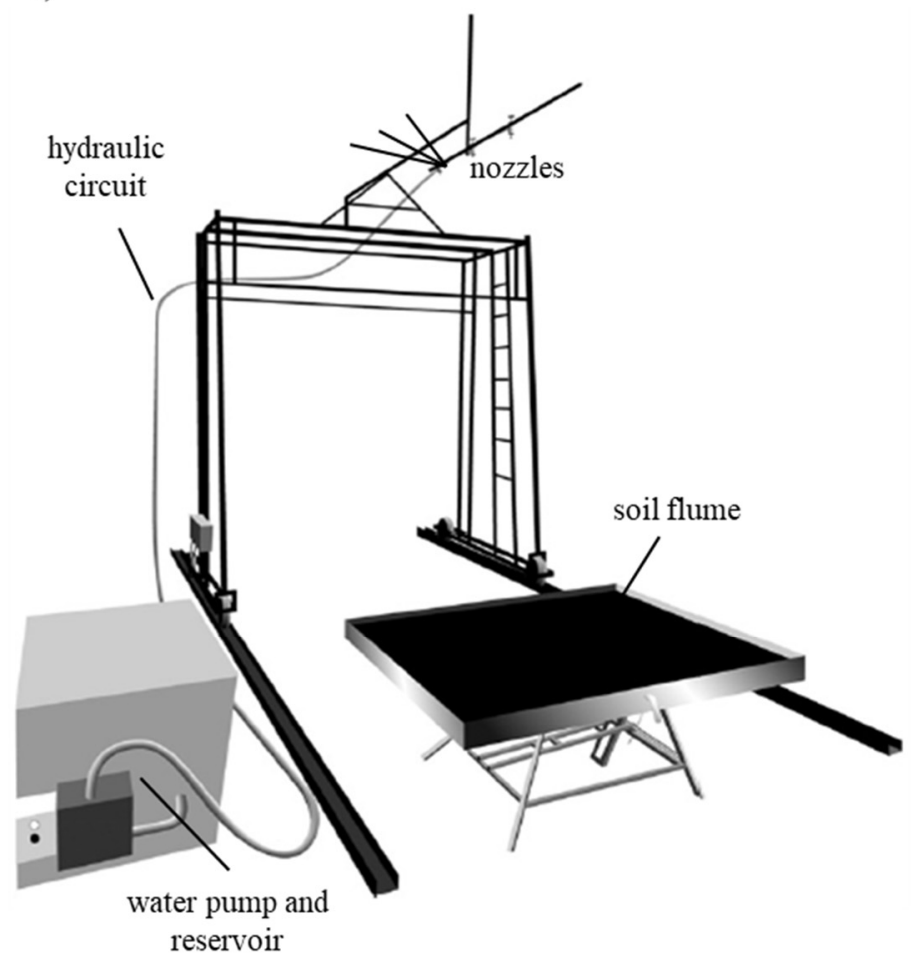

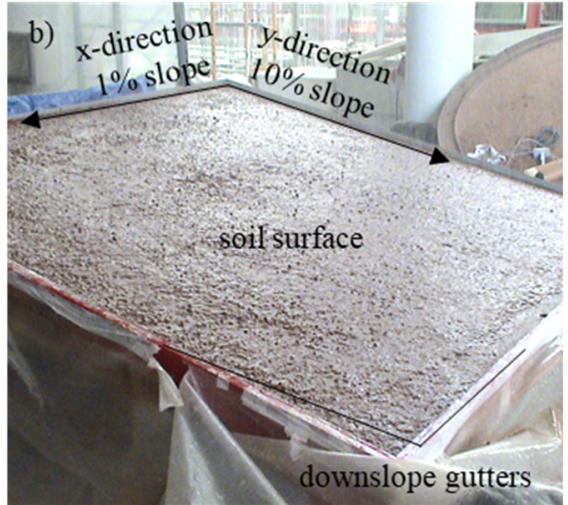

c)

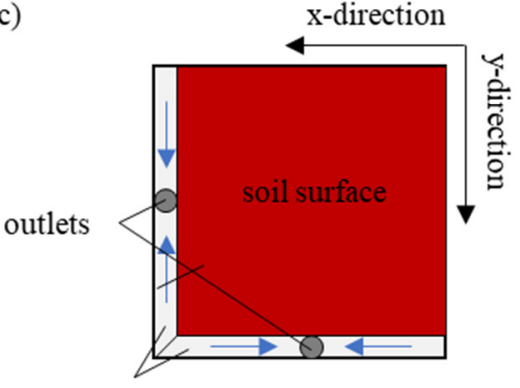

downslope gutters

Fig. 1. Experimental tests: a) Sketch of the laboratory set-up with the square soil flume and rainfall simulator comprising the water reservoir and pump, hydraulic circuit and nozzles (adapted from Deng et al., 2008); b) Photograph of the $2.00 \times 2.00 \mathrm{~m}^{2}$ soil flume with adjustable slope in $\mathrm{x}$-and $\mathrm{y}$-directions (represented by the arrows), with indication of downslope gutters; and c) Top-view scheme of the downslope gutters and outlets to where runoff is conveyed and collected.

in Fig. 1. The flume has a perforated bottom sheet covered with a geotextile blanket to allow for free drainage of percolated water underneath the soil layer. The $2.00 \times 2.00 \mathrm{~m}^{2}$ soil flume has adjustable slope in two directions, i.e. slope in $\mathrm{x}$-and $\mathrm{y}$-directions. The flume was adjusted to a slope of $1 \%$ in the $\mathrm{x}$ direction and $10 \%$ in the $y$-direction (Fig. 1b). Two gutters, each one placed along the downslope end of each slope direction, convey the surface runoff into two individual outlets (Fig. 1c).

The soil used in the experiments, characterised as sandyloam (USDA, 1993), was comprised of $11.5 \%$ clay, $9.8 \%$ silt, $78.7 \%$ sand. Prior to the experiments, the soil was air-dried, sieved through a $5 \mathrm{~mm}$ mesh screen and well mixed to ensure uniformity. The soil was uniformly spread in the flume over a geotextile to allow for free drainage of water. The topsoil was flattened and tapped to attain a smooth surface, i.e. without rough elements such as microtopographic protuberances. The soil layer presented an uniform bulk density of $1565 \mathrm{~kg} \mathrm{~m}^{-3}$ with a uniform thickness of $0.1 \mathrm{~m}$. Laboratory permeability tests yielded a saturated hydraulic conductivity of $5.70 \times 10^{-5}$ $\mathrm{m} \mathrm{s}^{-1}$ and a saturated soil water content of $39 \%$.

The rainfall simulator was comprised of three downwardoriented full-cone nozzles, a support structure, in which the nozzles were installed, and a hydraulic circuit connected to a water pump, water reservoir and tap water supply system from the public network. The nozzles (Fig. 1a) were positioned in a straight line with its direction parallel to the direction of the higher slope (i.e. y-direction), with an equal spacing of $0.95 \mathrm{~m}$ between them at an average height of $2.50 \mathrm{~m}$ from the geometric centre of the flume soil surface. The working pressure on the nozzles was kept approximately constant at $50 \mathrm{kPa}$, producing rainfall at an average intensity of $211 \mathrm{~mm} \mathrm{~h}^{-1}$ at the soil flume surface, with a uniformity coefficient of $64.6 \%$, calculated according to Christiansen (1942). Such extreme intensity was used previously in, e.g. Deng et al. (2008), to evaluate the performance of a soil erosion model. Spatial distribution of the rainfall intensity at the soil surface is shown in Fig. 2.

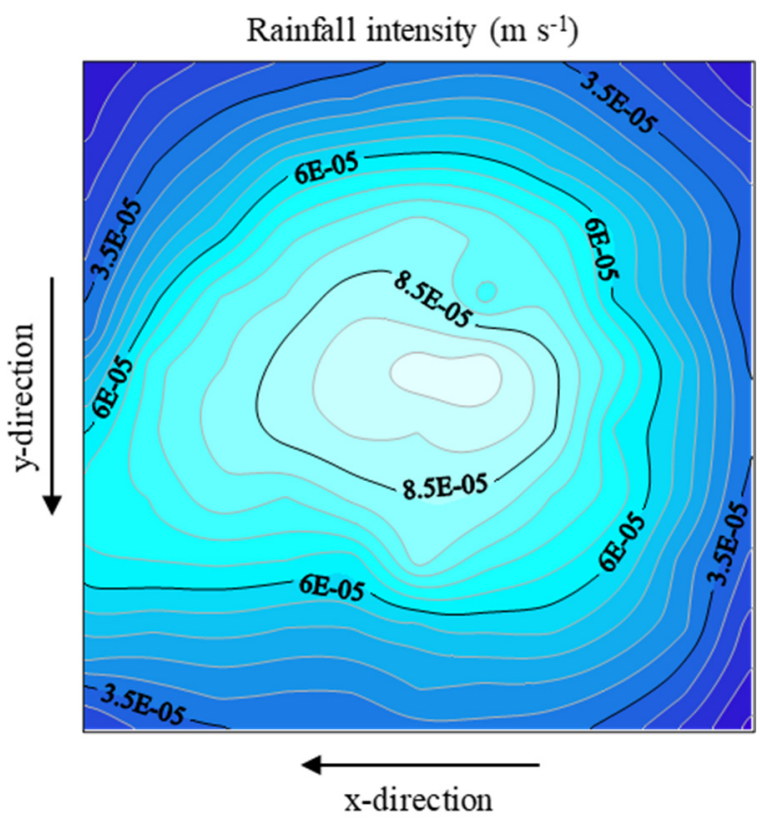

Fig. 2. Rainfall intensity spatial distribution at the soil surface level. Major isohyets (black lines) are in $\mathrm{m} \mathrm{s}^{-1}$. Interval between minor isohyets (grey lines) is $0.50 \times 10^{-5} \mathrm{~m} \mathrm{~s}^{-1}$. The arrows represent the slope in $\mathrm{x}$ - and $\mathrm{y}$-directions. 
The experiments consisted on four rainfall simulations each lasting $5 \mathrm{~min}$, with a $48 \mathrm{~h}$ interval of no rain between them. The first rainfall was simulated on an initially dry soil condition with a low soil water content of $0.1 \%$. Initial soil moisture for the following events was the resulting from the previous rainfall simulations and the $48 \mathrm{~h}$ drying period. After the end of an event, the amount of transported sediments was replaced for the next rainfall event. This was done by removing the entire 10 $\mathrm{mm}$ of topsoil layer, mixing it with the replacing amount of soil and spreading it uniformly in the flume over the remaining 90 $\mathrm{mm}$ of soil layer. The new topsoil was flattened and tapped to attain a new smooth soil surface, similar to the one in the beginning of the experiments.

Samples of surface runoff of the $\mathrm{x}$ - and $\mathrm{y}$-directions were collected separately at the two outlets located at the downslope end of the soil flume, using metal containers. Sediments transported by surface runoff were estimated by drying of samples at a temperature of $110^{\circ} \mathrm{C}$ for $24-48 \mathrm{~h}$, in a low temperature oven. Free water percolation below the flume was not measured.

\section{Model parameterisation}

The following parameters were estimated using the data collected from the laboratory experiments: i) Clear water density $(\rho)$ and kinematic viscosity $(v)$, for water at a temperature of $20^{\circ} \mathrm{C}$, were fixed in $998.2 \mathrm{~kg} \mathrm{~m}^{-3}$ and $1.003 \times 10^{-6} \mathrm{~m}^{2} \mathrm{~s}^{-1}$, respectively, according to Vennard and Street (1975); ii) Mean sediment particle diameter $\left(d_{s}\right)$ was estimated from the soil granulometric analysis and was fixed to $4.00 \times 10^{-4} \mathrm{~m}$; iii) Soil porosity $\left(p_{s}\right)$ was estimated as equivalent to the saturated water content and was fixed to 0.39 ; and iv) Sediment particles density $\left(\rho_{s}\right)$ was estimated using the measured soil bulk density of $1565 \mathrm{~kg} \mathrm{~m}^{-3}$ and estimated porosity of 0.39 and was fixed on $2566 \mathrm{~kg} \mathrm{~m}^{-3}$.

The following parameters were estimated using the data from similar experimental work using the same laboratory setup (i.e. soil, soil flume, rainfall simulator) and similar numerical work using similar numerical equations to express soil erosion (Deng et al., 2008): i) Manning's roughness coefficient (n) was fixed to $0.0265 \mathrm{~s} \mathrm{~m}^{-1 / 3}$; and ii) Interrill and rill erosion control parameters $\left(\eta\right.$ and $\xi$ ) were fixed in $1.38 \mathrm{~m}^{-1}$ and $8.20 \times$ $10^{-6} \mathrm{~m}$, respectively.

The dimensionless critical Shields parameter $\left(\theta_{c}\right)$ was estimated from Petit (1994) and was fixed on 0.047.

The parameters involved in the numerical simulation of infiltration $\left(C N\right.$ and $\left.c_{f}\right)$ were obtained after calibration till achievement of the best model performance. Such parameters are listed in Table 1.

Spatial discretization in both $\mathrm{x}$ - and y-directions ( $\Delta x$ and $\Delta y$ ) was fixed to $0.01 \mathrm{~m}$.

Table 1. Infiltration parameters used in the proposed model, for each of the four rainfall-runoff events.

\begin{tabular}{lllll}
\hline Infiltration & \multicolumn{4}{l}{ Rainfall event } \\
\cline { 2 - 5 } parameter & $1^{\text {st }}$ & $2^{\text {nd }}$ & $3^{\text {rd }}$ & $4^{\text {th }}$ \\
\hline$C N(-)$ & 95.0 & 99.0 & 99.5 & 99.5 \\
$c_{f}(-)$ & 0.200 & 0.050 & 0.050 & 0.025 \\
\hline
\end{tabular}

\section{Model evaluation}

Different criteria were used to evaluate the performance of the numerical model. Firstly, the accuracy of estimated runoff peak $\left(Q_{p}\right)$ and volume $(V)$ and transported sediments peak $\left(Q s_{p}\right)$ and total mass $(M s)$ and was quantified using the relative error $\left(E_{r}\right)$ :

$$
E_{r}=\frac{O b s-M o d}{O b s} \times 100
$$

where Obs and Mod represent the observed and modelled data, respectively.

Secondly, the goodness of fit of the shape of the estimated runoff hydrographs and graphs of transported sediments was quantified using the Coefficient of determination $\left(r^{2}\right)$ and the Nash-Sutcliffe model efficiency coefficient (NS) according to Nash and Sutcliffe (1970):

$$
\begin{aligned}
& r^{2}=\left(\frac{\sum_{i=1}^{n}\left(\left(O b s_{i}-\overline{O b s}\right) \times\left(\operatorname{Mod}_{i}-\overline{M o d}\right)\right)}{\sqrt{\left(\sum_{i=1}^{n}\left(O b s_{i}-\overline{O b s}\right)^{2}\right) \times\left(\sum_{i=1}^{n}\left(\operatorname{Mod}_{i}-\overline{M o d}\right)^{2}\right)}}\right)^{2} \\
& N S=1-\frac{\sum_{i=1}^{n}\left(O b s_{i}-M_{i}\right)^{2}}{\sum_{i=1}^{n}\left(O b s_{i}-\overline{O b s}\right)^{2}}
\end{aligned}
$$

where $O b s_{\mathrm{i}}$ and $\mathrm{Mod}_{i}$ represent the observed and modelled data at point $i$, respectively, $\overline{O b s}$ and $\overline{M o d}$ represent the average observed and modelled data and $\mathrm{n}$ is the total number of data points.

\section{RESULTS AND DISCUSSION}

Graphs of experimentally observed (symbols) and numerically modelled (solid curves) runoff (left) and transported sediments (right) for the four simulated rainfall events, are shown in Fig. 3. Results of experimentally observed $(O b s)$ and numerically modelled $(\mathrm{Mod})$ runoff peak $\left(Q_{p}\right)$ and runoff volume $(V)$ and transported sediments peak $\left(Q s_{p}\right)$ and total mass $(M s)$, for the four rainfall-runoff events, are shown in Tables 2 and 3; the Relative error $\left(E_{r}\right)$, the Coefficient of determination $\left(r^{2}\right)$ and the Nash-Sutcliffe model efficiency coefficient (NS) comparing observed to modelled results are also shown.

When compared to the higher slope of $10 \%$ in the $y$ direction, the lower slope of $1 \%$ in the $\mathrm{x}$-direction produced remarkably lower runoff and transported sediments (Fig. 3). Overall, this situation was more pronounced in the numerical model than in the experimental tests (see $E_{r}$ in Tables 2 and 3). The numerical model significantly underestimated $\mathrm{x}$-direction runoff and transported sediments, both in terms of peak and total amounts. In terms of numerical modelling goodness of fit, this situation translated in a good performance in the $\mathrm{y}$-direction as opposed to a poor performance in the x-direction (see $r^{2}$ and NS in Tables 2 and 3). For the x-direction, NS was always negative for both runoff and transported sediments. For the y-direction, $N S$ was always higher than 0.75 meaning a very good performance. The poor performance observed for the $\mathrm{x}$-direction may be related to the numerical treatment considered to address the wetting/drying front. The numerical treatment considered in this study rectifies the negative depth, ensuring mass continuity. However, as observed in Martins et al. (2017), the momentum is not corrected which may result in spurious oscillations of the modelled data and poorer model performance. Despite this results, $r^{2}$ values were always higher than 0.75 , meaning a good correlation between observed and modelled data, even for the x-direction. Only runoff results in 
a)

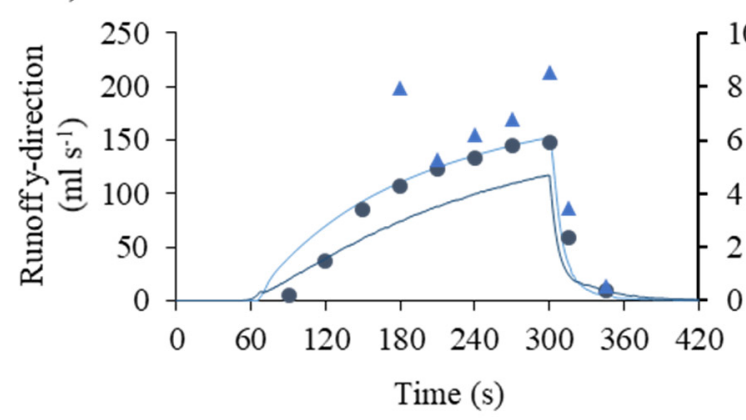

b)
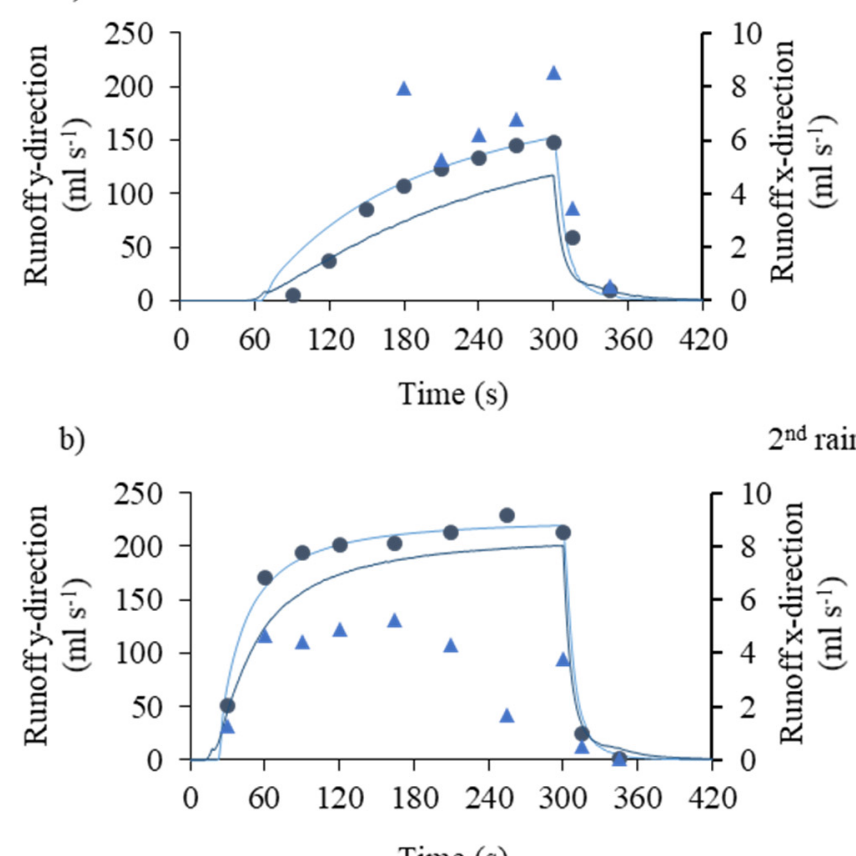

$1^{\text {st }}$ rainfall event

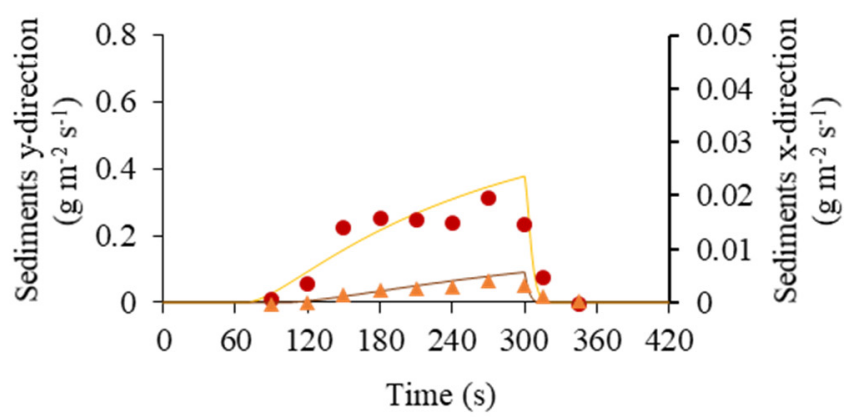

$2^{\text {nd }}$ rainfall event

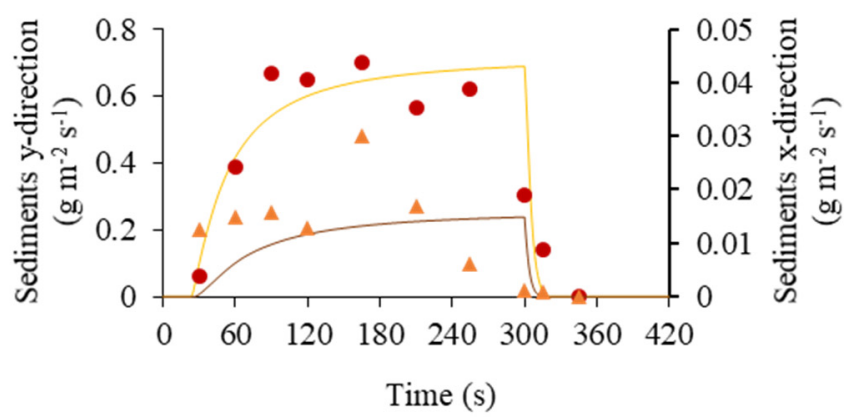

$3^{\text {rd }}$ rainfall event

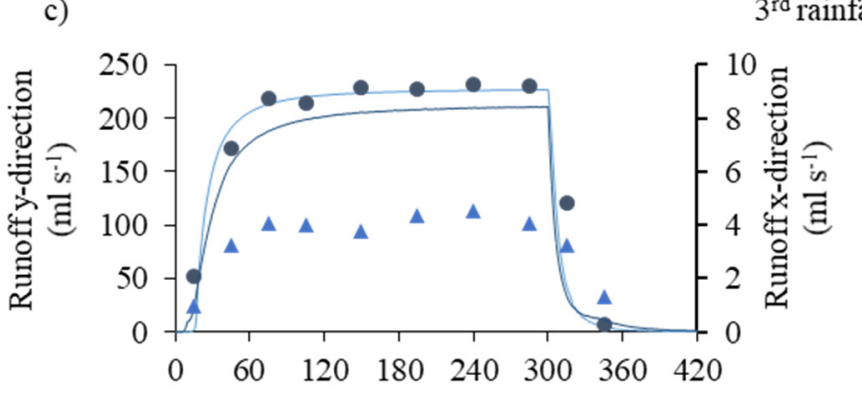

Time (s)

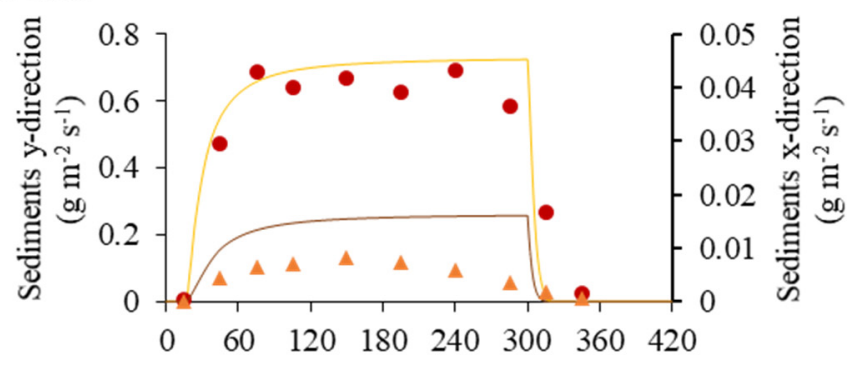

Time (s)

d)

$4^{\text {th }}$ rainfall event
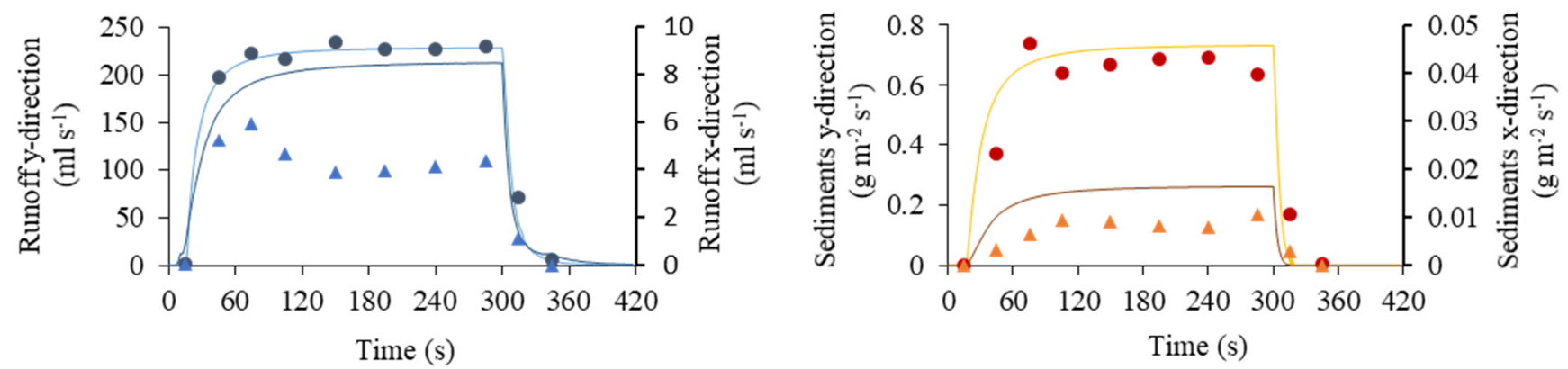

Observed x-direction

$\Delta$

Observed y-direction
Modelled x-direction

Modelled y-direction

Fig. 3. Graphs of observed (symbols) and modelled (solid curves) runoff (left) and transported sediments (right) fin the x-direction (primary axis) and y-direction (secondary axis, respectively) and for each of the four rainfall-runoff events: a) $1^{\text {st }}$ rainfall event; b) $2^{\text {nd }}$ rainfall event; c) $3^{\text {rd }}$ rainfall event; and d) $4^{\text {th }}$ rainfall event.

the $\mathrm{x}$-direction in the first rainfall event showed a different behaviour from the other results. Here, x-direction runoff was overestimated and $r^{2}$ value was close to 0 .

As expected, due to the initial dry soil condition, observed time to runoff was significantly higher in the first rainfall event (60 s) when compared to the following events (20, 15 and $14 \mathrm{~s})$. Also, the hydrograph and sediment transport graph in the first event presented significantly less steep rising limbs and lower peaks. The last three rainfall events presented similar results due to the similar initial wet condition of the soil (i.e. 24 h dry period between rainfall events). In numerical terms, since infiltration parameters were calibrated according to each rainfall event, the initial soil moisture condition did not have a visible impact in the performance model. 
Table 2. Observed $(\mathrm{Obs})$ and modelled $(\mathrm{Mod})$ results of runoff peak $\left(Q_{p}\right)$ and runoff volume $(V)$ for the four rainfall-runoff events. Relative error $\left(E_{r}\right)$, Coefficient of determination $\left(r^{2}\right)$ and Nash-Sutcliffe model efficiency coefficient $(N S)$ are shown.

\begin{tabular}{|c|c|c|c|c|c|c|c|c|}
\hline \multirow[t]{3}{*}{ Rainfall event } & \multirow{3}{*}{ Direction } & \multirow[t]{3}{*}{ Data } & \multicolumn{6}{|l|}{ Runoff } \\
\hline & & & \multicolumn{2}{|l|}{$Q_{p}$} & \multicolumn{2}{|l|}{$V$} & \multirow[t]{2}{*}{$r^{2}$} & \multirow[t]{2}{*}{$N S$} \\
\hline & & & $\mathrm{ml} \mathrm{s}^{-1}$ & $E_{r}(\%)$ & 1 & $E_{r}(\%)$ & & \\
\hline \multirow[t]{6}{*}{1} & \multirow[t]{2}{*}{$\mathrm{x}$} & Obs & 22.94 & \multirow{2}{*}{79.57} & 2.39 & \multirow{2}{*}{69.47} & \multirow[b]{2}{*}{0.02} & \multirow{2}{*}{-1.16} \\
\hline & & Mod & 4.69 & & 0.73 & & & \\
\hline & \multirow[t]{2}{*}{$\mathrm{y}$} & $O b s$ & 149.06 & \multirow{2}{*}{-2.38} & 24.18 & \multirow{2}{*}{-6.56} & \multirow{2}{*}{0.93} & \multirow{2}{*}{0.90} \\
\hline & & Mod & 152.61 & & 25.77 & & & \\
\hline & \multirow[t]{2}{*}{ Total } & $O b s$ & 157.67 & \multirow[b]{2}{*}{0.23} & 26.58 & \multirow{2}{*}{0.29} & \multirow{2}{*}{0.96} & \multirow{2}{*}{0.95} \\
\hline & & Mod & 157.30 & & 26.50 & & & \\
\hline \multirow[t]{6}{*}{2} & \multirow[t]{2}{*}{$\mathrm{x}$} & Obs & 5.34 & \multirow{2}{*}{-50.39} & 1.09 & \multirow{2}{*}{-80.33} & \multirow{2}{*}{0.51} & \multirow{2}{*}{-2.61} \\
\hline & & Mod & 8.03 & & 1.97 & & & \\
\hline & \multirow{2}{*}{$\mathrm{y}$} & $O b s$ & 228.73 & & 55.70 & 0 72 & 090 & 0.99 \\
\hline & & Mod & 219.52 & 4.03 & 56.09 & -0.12 & 0.99 & 0.99 \\
\hline & Total & $O b s$ & 230.43 & 125 & 56.79 & & 099 & \\
\hline & & Mod & 227.55 & 1.25 & 58.06 & -2.25 & 0.99 & 0.98 \\
\hline 3 & $\mathrm{x}$ & $O b s$ & 4.58 & & 1.25 & & 080 & \\
\hline & & Mod & 8.43 & -84.05 & 2.28 & -82.28 & 0.80 & -12.99 \\
\hline & $\mathrm{y}$ & Obs & 232.15 & 241 & 64.11 & 215 & 0.96 & 099 \\
\hline & & Mod & 226.54 & 2.41 & 62.73 & $2.1 \mathrm{~J}$ & 0.30 & 0.92 \\
\hline & Total & Obs & 236.66 & 071 & 65.36 & 0.54 & 0.96 & 0.92 \\
\hline & & Mod & 234.97 & 0.11 & 65.01 & 0.34 & 0.90 & 0.92 \\
\hline 4 & $\mathrm{x}$ & Obs & 5.96 & -4231 & 1.27 & -8139 & 0.83 & -3.01 \\
\hline & & Mod & 8.49 & 42.51 & 2.30 & -01.5 & $0.0 \mathrm{~J}$ & -5.01 \\
\hline & $\mathrm{y}$ & Obs & 237.82 & 4.15 & 63.68 & 0.51 & 099 & 098 \\
\hline & & Mod & 227.95 & 4.13 & 63.35 & 0.31 & 0.99 & 0.98 \\
\hline & Total & Obs & 241.80 & 222 & 64.95 & -109 & 0.99 & 0.98 \\
\hline & & Mod & 236.44 & 2.22 & 65.66 & -1.09 & 0.99 & 0.90 \\
\hline
\end{tabular}

Table 3. Observed $(O b s)$ and modelled $(M o d)$ results of transported sediment peak $\left(Q s_{p}\right)$ and total mass $(M s)$ for the four rainfall-runoff events. Relative error $\left(E_{r}\right)$, Coefficient of determination $\left(r^{2}\right)$ and Nash-Sutcliffe model efficiency coefficient $(N S)$ are shown.

\begin{tabular}{|c|c|c|c|c|c|c|c|c|}
\hline \multirow[t]{3}{*}{ Rainfall event } & \multirow[t]{3}{*}{ Direction } & \multirow[t]{3}{*}{ Data } & \multicolumn{6}{|c|}{ Transported sediments } \\
\hline & & & \multicolumn{2}{|c|}{$Q s_{p} \times 10^{2}$} & \multicolumn{2}{|l|}{$M s$} & \multirow[t]{2}{*}{$r^{2}$} & \multirow[t]{2}{*}{$N S$} \\
\hline & & & $\mathrm{g} \mathrm{m}^{2} \mathrm{~s}^{-1}$ & $E_{r}(\%)$ & $\mathrm{g}$ & $E_{r}(\%)$ & & \\
\hline \multirow[t]{6}{*}{1} & \multirow[t]{2}{*}{$\mathrm{x}$} & Obs & 0.50 & \multirow{2}{*}{-13.70} & 2.31 & \multirow{2}{*}{-2.83} & \multirow{2}{*}{0.79} & \multirow{2}{*}{-0.79} \\
\hline & & Mod & 0.57 & & 2.38 & & & \\
\hline & \multirow{2}{*}{$\mathrm{y}$} & $O b s$ & 34.07 & \multirow{2}{*}{-10.89} & 188.97 & \multirow{2}{*}{-7.95} & \multirow{2}{*}{0.85} & \multirow{2}{*}{0.80} \\
\hline & & Mod & 37.78 & & 204.00 & & & \\
\hline & \multirow[t]{2}{*}{ Total } & $O b s$ & 34.57 & \multirow{2}{*}{-10.93} & 191.28 & \multirow{2}{*}{-7.89} & \multirow{2}{*}{0.85} & \multirow{2}{*}{0.80} \\
\hline & & Mod & 38.35 & & 206.38 & & & \\
\hline \multirow[t]{6}{*}{2} & \multirow[t]{2}{*}{$\mathrm{x}$} & Obs & 4.96 & \multirow{2}{*}{70.03} & 17.26 & \multirow{2}{*}{24.28} & \multirow{2}{*}{0.82} & \multirow{2}{*}{-0.08} \\
\hline & & Mod & 1.49 & & 13.07 & & & \\
\hline & \multirow[t]{2}{*}{$\mathrm{y}$} & $O b s$ & 74.28 & 724 & 634.54 & -381 & 085 & 080 \\
\hline & & Mod & 68.90 & 1.24 & 658.74 & -5.01 & 0.03 & 0.00 \\
\hline & Total & $\mathrm{Obs}$ & 75.61 & 690 & 651.80 & -307 & 085 & 079 \\
\hline & & Mod & 70.39 & 0.90 & 671.81 & -5.01 & $0.0 \mathrm{~J}$ & 0.19 \\
\hline 3 & $\mathrm{x}$ & $O b s$ & 0.85 & -8847 & 6.86 & -13952 & 075 & -8.97 \\
\hline & & Mod & 1.61 & -00.41 & 16.44 & -107.02 & & -0.91 \\
\hline & $\mathrm{y}$ & Obs & 69.39 & -4.46 & 690.12 & -12.26 & 0.91 & 0.79 \\
\hline & & Mod & 72.49 & -4.40 & 774.73 & -12.20 & 0.91 & 0.19 \\
\hline & Total & $\mathrm{Obs}$ & 69.99 & -5.87 & 696.33 & -13.62 & 0.91 & 0.79 \\
\hline & & Mod & 74.10 & & 791.17 & -15.02 & & 0.13 \\
\hline 4 & $\mathrm{x}$ & Obs & 1.17 & -3922 & 9.28 & -80.77 & 087 & -202 \\
\hline & & Mod & 1.63 & 2 & 16.78 & 00.11 & 0.01 & 2.02 \\
\hline & $\mathrm{y}$ & Obs & 74.05 & 111 & 688.33 & -14.39 & 0.88 & 0.76 \\
\hline & & Mod & 73.23 & & 787.41 & 19.0 & & \\
\hline & Total & Obs & 74.69 & -0.22 & 697.61 & -15.28 & 0.88 & 0.76 \\
\hline & & Moa & 44.86 & & 804.19 & & & \\
\hline
\end{tabular}

Since runoff and transported sediments in the x-direction were almost meaningless, the numerical performance of the model in total terms (i.e. $x$ - plus y-direction) was considered to be very good. Overall, runoff was slightly better modelled than sediment transport. However, as stated before, the infiltration parameters were calibrated according to each rainfall event due to changes in initial soil moisture condition with the consecu- tive rainfall events; i.e. the initial soil moisture of an event was the resulting from the previous rainfall simulation. On the contrary, sediment transport parameters were not calibrated; they were estimated using data collected from laboratory experiments and were fixed for all rainfall events. Even so, the performance of the model in simulating the total sediment transport was very good. 
Two-dimensional (2D) numerical modelling of rainfall induced overland flow, infiltration and soil erosion

This study started from the premiss that a two-dimensional model will perform better than a one-dimensional model in the case of spatially distributed rainfall. It is acknowledged that rainfall spatial distribution is often heterogeneous and complex, and its adequate representation is crucial to accurate runoff prediction (Beven et al., 2012). In this sense, only twodimensional distributed models, as the one in developed in this study, fully represent and explore the heterogeneity and complexity of the rainfall spatial distribution. However, only a comparison with results from a one-dimensional model can ascertain this premise.

The developed model presented in this study considered steady flat soil surface and therefore did not considered the spatiotemporal evolution of the soil surface microrelief due to erosion processes, such as the formation of rills and depressions. The same simplification is common in many soil erosion models, including USLE (Wischmeier and Smith, 1978), RUSLE (Renard et al., 1997), KINEROS (Woolhiser et al., 1990), WEPP (Flanagan and Nearing, 1995) and EUROSEM (Morgan et al., 1998). The not consideration of the complex changes of the soil surface microrelief may result in large errors in soil erosion modelling $\mathrm{Wu}$ et al. (2020). However, in the present laboratory experiments with a short duration rainfall and small scale soil flume, no significant relief features, such as rills, have formed on the soil surface. Therefore, despite the possible errors due to this simplification, it is not expected that they have been significant.

\section{CONCLUSION}

A two-dimensional mathematical model was developed for simulating soil erosion and sediment transport resulting from rainfall induced overland flow. The model comprised: i) Twodimensional unsteady water flow equations on an infiltrating surface; ii) Combined Horton-SCS infiltration scheme; and iii) Two-dimensional sediment transport equation with three distinct soil erosion processes (interrill erosion, rill erosion and sediment deposition).

Overall, if the sum of the $\mathrm{x}$ - and $\mathrm{y}$-direction results is considered, the numerically simulated graphs of runoff and sediment transport were in very good agreement with corresponding experimental measurements, demonstrating the laboratory proof-of-concept of the model. However, if $\mathrm{x}$ - and $\mathrm{y}$-directions results are analysed separately, the numerical model was only able to properly simulate the runoff and sediment transport observed in the y-direction with the higher slope of $10 \%$. A poor agreement was observed for the remarkably lower values of runoff and sediment transport observed in the x-direction with the lower slope of $1 \%$. Overall, since the infiltration parameters were calibrated, the initial moisture condition of the soil did not had impact on the performance of the numerical model.

Naturally, the results from this study limits the model to the descriptions of the known experimental conditions and extrapolations beyond those limits should not be made, e.g. the artificial soil sample with disturbed/sieved soil, the flat surface does not represent natural soil conditions and the steady state of the surface does not represent the spatiotemporal evolution of the soil surface microrelief. Therefore, future tests should be conducted to evaluate the performance of the model in more complex and natural field conditions and other temporal and spatial scales, such as longer rainfall events at hillslope scale.

Acknowledgements. The authors acknowledge the financial support of FCT, Portugal, through the Projects ASHMOB
(CENTRO-01-0145-FEDER-029351),

MUSSELFLOW (PTDC/BIA-EVL/29199/2017), MEDWATERICE (PRIMASection2-2018) and the Strategic project UID/MAR/04292/2013 granted to MARE, Portugal.

\section{REFERENCES}

Abrantes, J.R.C.B., de Lima, J.L.M.P., Montenegro, A.A.A., 2015. Performance of kinematic modelling of surface runoff for intermittent rainfall on soils covered with mulch (in Portuguese). Rev. Bras. Eng. Agr. Amb., 19, 2, 166-172. https://doi.org/10.1590/1807-1929/agriambi.v19n2p166-172

Abrantes, J.R.C.B., Prats, S.A., Jacob, J.K., de Lima, J.L.M.P., 2018. Effectiveness of the application of rice straw mulching strips in reducing runoff and soil loss: Laboratory soil flume experiments under simulated rainfall. Soil Tillage Res., 180, 238-249. https://doi.org/10.1016/j.still.2018.03.015

Abrantes, J.R.C.B., Moruzzi, R.B., de Lima, J.L.M.P., Silveira, A., Montenegro, A.A.A., 2019. Combining a thermal tracer with a transport model to estimate shallow flow velocities. Phys. Chem. Earth, 109, 59-69. https://doi.org/10.1016/j.pce.2018.12.005

Batista, P.V.G., Davies, J., Silva, M.L.N., Quinton, J.N., 2019. On the evaluation of soil erosion models: Are we doing enough? Earth Sci. Rev., 197, 102898. https://doi.org/10.1016/j.earscirev.2019.102898

Beven, K.J., 2012. Rainfall-Runoff Modelling: The Primer. 2nd ed. Wiley-Blackwell, Chichester, UK.

Boardman, J., Shepheard, M.L., Walker, E., Foster, I.D.L., 2009. Soil erosion and risk-assessment for on- and off-farm impacts: A test case using the Midhurst area, West Sussex, UK. J. Environ. Manage., 90, 8, 2578-2588. https://doi.org/10.1016/j.jenvman.2009.01.018

Cao, Z., Pender, G., Wallis, S., Carling, P., 2002. Computational dam-break hydraulics over erodible sediment bed. J. Hydraul. $\quad$ Eng., 128, 5, 460-72. https://doi.org/10.1061/(ASCE)0733-9429(2004)130:7(689)

Cheng, N.S., 1997. Simplified settling velocity formula for sediment particle. J. Hydraul. Eng., 123, 2, 149-152. https://doi.org/10.1061/(ASCE)0733-9429(1997)123:2(149)

Christiansen, J.E., 1942. Irrigation by Sprinkling. California Agricultural Experiment Station Bulletin 670. University of California, Berkeley, CA, USA.

Cuomo, S., Della Sala, M., Pierri, M., 2016. Experimental evidences and numerical modelling of runoff and soil erosion in flume tests. Catena, 147, 61-70. https://doi.org/10.1016/j.catena.2016.06.044

de Lima, J.L.M.P., Carvalho, S.C.P., de Lima, M.I.P., 2013. Rainfall simulator experiments on the importance of when rainfall burst occurs during storm events on runoff and soil loss. Z. Geomorphol., 57, 1, 91-109. https://doi.org/10.1127/0372-8854/2012/S-00096

de Lima, J.L.M.P., Santos, L., Mujtaba, B., de Lima, M.I.P., 2019. Laboratory assessment of the influence of rice straw mulch size on soil loss. Adv. Geosci., 48, 11-18. https://doi.org/10.5194/adgeo-48-11-2019

Deng, Z.Q., de Lima J.L.M.P., Singh, V.P., 2005. Transport rate-based model for overland flow and solute transport: $\mathrm{Pa}-$ rameter estimation and process simulation. J. Hydrol., 315, 1-4, 220-235. https://doi.org/10.1016/j.jhydrol.2005.03.042

Deng, Z.Q., de Lima, J.L.M.P., Jung, H.S., 2008. Sediment transport rate-based model for rainfall-induced soil erosion. Catena, 76, 1, 54-62. https://doi.org/10.1016/j.catena.2008.09.005

Esteves, M., Faucher, X., Galle, S., Vauclin, M., 2000. Overland flow and infiltration modelling for small plots during 
unsteady rain: numerical results versus observed values. J. Hydrol., 228, 3-4, 265-282. https://doi.org/10.1016/S00221694(00)00155-4

Flanagan, D.C., Nearing, M.A., 1995. USDA-Water Erosion Prediction Project: Hillslope Profile and Watershed Model Documentation. NSERL Report No. 10. USDA-ARS, National Soil Erosion Research, West Lafayette, IN, USA.

Gabellani, S., Silvestro, F., Rudari, R., Boni, G., 2008. General calibration methodology for a combined Horton-SCS infiltration scheme in flash flood modeling. Nat. Hazards Earth Sys. Sci., 8, 6, 1317-1327. https://doi.org/10.5194/nhess-8$1317-2008$

Garcia, R., Kahawita, R.A., 1986. Numerical solution of the St. Venant equations with the MacCormack finite-difference scheme. Int. J. Numer. Meth. Fluids, 6, 5, 259-274. https://doi.org/10.1002/fld.1650060502

Horton, R., 1933. The role of infiltration in the hydrological cycle. Trans. Am. Geophys. Union, 14, 1, 446-460. https://doi.org/10.1029/TR014i001p00446

Isidoro J.M.G.P., de Lima J.L.M.P., 2013. An analytical closed form solution for 1D kinematic overland flow under moving rainstorms. J. Hydrol. Eng., 18, 9, 1148-1156. https://doi.org/10.1061/(ASCE)HE.1943-5584.0000740

Kinnell, P.I.A., 2005. Raindrop-impact-induced erosion processes and prediction: a review. Hydrol. Proc., 19, 14, 28152844. https://doi.org/10.1002/hyp.5788

Liu, X., Beljadid, A., 2017. A coupled numerical model for water flow, sediment transport and bed erosion. Comput. Fluids, 154, 273-284. https://doi.org/10.1016/j.compfluid.2017.06.013

MacCormack, R.W., 1971. Numerical solution of the interaction of a shock wave with a laminar boundary layer. In: Holt M. (Eds.): Proceedings of the Second International Conference on Numerical Methods in Fluid Dynamics. Lecture Notes in Physics, 8. Springer, Heidelberg, Germany.

Martins, R., Leandro, J., Djordjević, S., 2018. Wetting and drying numerical treatments for the Roe Riemann scheme. J. Hydraul. Res., 56, 2, 256-267. https://doi.org/10.1080/00221686.2017.1289256

Montenegro, A.A.A., Abrantes, J.R.C.B., de Lima, J.L.M.P., Singh, V.P., Santos, T.E.M., 2013. Impact of mulching on soil and water dynamics under intermittent simulated rainfall. Catena, 109, 139-149. https://doi.org/10.1016/j.catena.2013.03.018

Montgomery, D.R., 2007. Dirt: The Erosion of Civilizations. University of California Press, Berkeley, CA, USA.

Morgan, R.P.C., Quinton, J.N., Smith, R.E., Govers, G., Poesen, J.W.A., Auerswald, K., Chisci, G., Torri, D., Styczen, M.E., 1998. The European Soil Erosion Model (EUROSEM): a dynamic approach for predicting sediment transport from fields and small catchments. Earth Surf. Process. Landf., 23, 527-544. https://doi.org/10.1002/(SICI)10969837(199806)23:6<527::AID-ESP868>3.0.CO;2-5

Nash, J.E., Sutcliffe, J.V., 1970. River flow forecasting through conceptual models part I - a discussion of principles, J. Hydrol., 10, 3, 282-290. https://doi.org/10.1016/00221694(70)90255-6

Nearing, M.A., 2000. Evaluating soil erosion models using measured plot data: accounting for variability in the data. Earth Surf. Process. Landf., 25, 1035-1043. https://doi.org/10.1002/1096-9837(200008)25:9<1035::AIDESP121>3.0.CO;2-B
Panagos, P., Katsoyiannis, A., 2019. Soil erosion modelling: The new challenges as the result of policy developments in Europe. Environ. Res., 172, 470-474. https://doi.org/10.1016/j.envres.2019.02.043

Prats, S.A., Abrantes, J.R.C.B., Crema, I.P., Keizer, J.J., de Lima, J.L.M.P., 2017. Runoff and soil erosion mitigation with sieved forest residue mulch strips under controlled laboratory conditions. Forest Ecol. Manag., 396, 102-112. https://doi.org/10.1016/j.foreco.2017.04.019

Renard, K., Foster, G.R., Weesies, G.A., McCool, D.K., Yoder, D.C., 1997. Predicting Soil Erosion by Water: A Guide to Conservation Planning with the Revised Universal Soil Loss Equation (RUSLE). Agricultural Handbook 703, USDAARS, Southwest Watershed Research Center, Tucson, AZ, USA.

Rickson, R.J., 2014. Can control of soil erosion mitigate water pollution by sediments? Sci. Total Environ., 468-469, 11871197. https://doi.org/10.1016/j.scitotenv.2013.05.057

Silveira, A., Abrantes, J.R.C.B., de Lima, J.L.M.P., Lira, L.C., 2016. Modelling runoff on ceramic tile roofs using the kinematic wave equations. Water Sci. Technol., 73, 11, 28242831. https://doi.org/10.2166/wst.2016.148

Simões, N.E., 2006. Modelação bidimensional de escoamentos variáveis em superfície livre: aplicação ao estudo de cheias. Master's Thesis. Faculty of Sciences and Technology of the University of Coimbra, Coimbra, Portugal. (In Portuguese.)

Singh, V.P., de Lima, J.L.M.P., 2018. One-dimensional linear kinematic wave solution for overland flow under moving storms using the method of characteristics. J. Hydrol. Eng., 23, 7, 04018029. https://doi.org/10.1061/(ASCE)HE.19435584.0001676

Singh, V.P., Woolhiser, D.A., 2002. Mathematical modeling of watershed hydrology. J. Hydrol. Eng., 7, 4, 270-292. https://doi.org/10.1061/(ASCE)1084-0699(2002)7:4(270)

Stroosnijder, L., 2005. Measurement of erosion: Is it possible? Catena, 64, 162-173. https://doi.org/10.1016/j.catena.2005.08.004

USDA, 1993. Soil Survey Manual, USDA-SCS Handbook 18. U.S. Government Publishing Office, Washington, DC, USA. USDA, 2004. National Engineering Handbook, Section 4. U.S. Department of Agriculture, Washington, DC, USA.

Vennard, J.K., Street, R.L., 1975. Elementary Fluid Mechanics, 5th ed. Wiley, New York, NY, USA.

Wischmeier, W.H., Smith, D., 1978. Predicting RainfallErosion Losses: A Guide to Conservation Planning. Agriculture Handbook No. 537, USDA, Washington, DC, USA.

Woolhiser, D.A., Smith, R.E., Goodrich, D.C., 1990. KINEROS: A Kinematic Runoff and Erosion Model: Documentation and User Manual. USDA-ARS-77, West Lafayette, IN, USA.

Wu, S., Chen, Li., Wang, N., Li, J., Li, J. 2020. Twodimensional rainfall-runoff and soil erosion model on an irregularly rilled hillslope. J. Hydrol., 580, 124346. https://doi.org/10.1016/j.jhydrol.2019.124346

Zhang, W., Cundy, T.W., 1989. Modeling of two dimensional overland flow. Water Resour. Res., 25, 9, 2019-2035. https://doi.org/10.1029/WR025i009p02019

Received 30 September 2019 Accepted 21 December 2020 


\section{APPENDIX A}

\section{MacCormack scheme}

In this paper, the governing equations were solved using the explicit finite-difference method based on the MacCormack operator-splitting scheme (Garcia and Kahawita, 1986; MacCormack, 1971; Simões, 2006). For simplification, Equations (1-3) and (5) were further rewritten in the following vector format:

$\frac{\partial \boldsymbol{U}}{\partial t}+\frac{\partial \boldsymbol{E} \boldsymbol{x}}{\partial x}+\frac{\partial \boldsymbol{E} \boldsymbol{y}}{\partial y}=g h\left(\frac{\partial \boldsymbol{Z x}}{\partial x}+\frac{\partial \boldsymbol{Z} \boldsymbol{y}}{\partial y}\right)+\boldsymbol{G}$

in which:

$\boldsymbol{U}=\left[\begin{array}{c}h \\ v_{x} h \\ v_{y} h \\ h c\end{array}\right], \quad \boldsymbol{E} \boldsymbol{x}=\left[\begin{array}{c}v_{x} h \\ v_{x}{ }^{2} h+\frac{1}{2} g h^{2} \\ v_{x} v_{y} h \\ v_{x} h c\end{array}\right], \quad \boldsymbol{E} \boldsymbol{y}=\left[\begin{array}{c}v_{y} h \\ v_{x} v_{y} h \\ v_{y}{ }^{2} h+\frac{1}{2} g h^{2} \\ v_{y} h c\end{array}\right]$,

$\boldsymbol{Z} \boldsymbol{x}=\left[\begin{array}{c}0 \\ -Z \\ 0 \\ 0\end{array}\right], \quad \boldsymbol{Z} \boldsymbol{y}=\left[\begin{array}{c}0 \\ 0 \\ -Z \\ 0\end{array}\right], \quad \boldsymbol{G}=\left[\begin{array}{c}p-i \\ -g h S_{f x} \\ -g h S_{f y} \\ e-d\end{array}\right]$

Eq. (A1) was divided into two separate one-dimensional problems by the operator-splitting technique as:

$\frac{\partial \boldsymbol{U}}{\partial t}+\frac{\partial \boldsymbol{E} \boldsymbol{x}}{\partial x}=g h \frac{\partial \boldsymbol{Z} \boldsymbol{x}}{\partial x}+\boldsymbol{G} \quad, \quad \frac{\partial \boldsymbol{U}}{\partial t}+\frac{\partial \boldsymbol{E} \boldsymbol{y}}{\partial y}=g h \frac{\partial \boldsymbol{Z} \boldsymbol{y}}{\partial y}+\boldsymbol{G}$

where the solution of $\boldsymbol{U}$ at time $(n+1) \Delta t$, for the computational point $(i, j)$, i.e. $\mathrm{U}(i \Delta t, j \Delta t,(n+1) \Delta t)$, can be obtained as follows:

$\boldsymbol{U}_{i, j}^{n+1}=L x_{1} \frac{\Delta t}{2} L y_{1} \frac{\Delta t}{2} L y_{2} \frac{\Delta t}{2} L x_{2} \frac{\Delta t}{2} \boldsymbol{U}_{i, j}^{n}$

where $L x$ and $L y$ are one-dimensional finite-difference operators, each one composed of a predictor-corrector computational sequence.

In each of the $L x$ and $L y$ operators, the solution is advanced by a time step $\Delta t / 2$ as if the derivatives in the other direction were absent. Therefore, each operator is computed twice to gain the solution at the next step.

Taking $L x_{1}$ and $L y_{1}$ operators as example, their solution can be written as:

$L x_{1}$ predictor sequence (backward differences):

$\boldsymbol{U}_{i, j}^{p}=\boldsymbol{U}_{i, j}^{o}-\frac{\Delta t}{2 \Delta x}\left(\boldsymbol{E} \boldsymbol{x}_{i, j}^{o}-\boldsymbol{E} \boldsymbol{x}_{i-1, j}^{o}\right)+g\left(\frac{h_{i, j}^{o}+h_{i-1, j}^{o}}{2}\right) \frac{\Delta t}{2 \Delta x}\left(\boldsymbol{Z} \boldsymbol{x}_{i, j}^{o}-\boldsymbol{Z x}_{i-1, j}^{o}\right)+\frac{\Delta t}{2}\left(\frac{\boldsymbol{G}_{i, j}^{o}+\boldsymbol{G}_{i-1, j}^{o}}{2}\right)$

$L x_{1}$ corrector sequence (forward differences):

$\boldsymbol{U}_{i, j}^{c}=\frac{1}{2}\left[\boldsymbol{U}_{i, j}^{o}+\boldsymbol{U}_{i, j}^{p}-\frac{\Delta t}{2 \Delta x}\left(\boldsymbol{E x}_{i+1, j}^{p}-\boldsymbol{E} \boldsymbol{x}_{i, j}^{p}\right)+g\left(\frac{h_{i+1, j}^{p}+h_{i, j}^{p}}{2}\right) \frac{\Delta t}{2 \Delta x}\left(\boldsymbol{Z x}_{i+1, j}^{p}-\boldsymbol{Z} \boldsymbol{x}_{i, j}^{p}\right)+\frac{\Delta t}{2}\left(\frac{\boldsymbol{G}_{i+1, j}^{o}+\boldsymbol{G}_{i, j}^{o}}{2}\right)\right]$

$L y_{1}$ predictor sequence (forward differences):

$\boldsymbol{U}_{i, j}^{p}=\boldsymbol{U}_{i, j}^{o}-\frac{\Delta t}{2 \Delta y}\left(\boldsymbol{E} \boldsymbol{y}_{i, j}^{o}-\boldsymbol{E} \boldsymbol{y}_{i, j-1}^{o}\right)+g\left(\frac{h_{i, j}^{p}+h_{i, j-1}^{p}}{2}\right) \frac{\Delta t}{2 \Delta y}\left(\boldsymbol{Z} \boldsymbol{y}_{i, j}^{o}-\boldsymbol{Z}_{i, j-1}^{o}\right)+\frac{\Delta t}{2}\left(\frac{\boldsymbol{G}_{i, j}^{o}+\boldsymbol{G}_{i, j-1}^{o}}{2}\right)$

$L y_{1}$ corrector sequence (backward differences):

$\boldsymbol{U}_{i, j}^{c}=\frac{1}{2}\left[\boldsymbol{U}_{i, j}^{o}+\boldsymbol{U}_{i, j}^{p}-\frac{\Delta t}{2 \Delta y}\left(\boldsymbol{E} \boldsymbol{y}_{i, j+1}^{p}-\boldsymbol{E y}_{i, j}^{p}\right)+g\left(\frac{h_{i, j+1}^{p}+h_{i, j}^{p}}{2}\right) \frac{\Delta t}{2 \Delta y}\left(\boldsymbol{Z y}_{i, j+1}^{p}-\boldsymbol{Z} \boldsymbol{y}_{i, j}^{p}\right)+\frac{\Delta t}{2}\left(\frac{\boldsymbol{G}_{i, j+1}^{o}+\boldsymbol{G}_{i, j}^{o}}{2}\right)\right]$ 
where the superscript $o$ indicates that results from the previous operator (or time step in case of $L x_{1}$ ) should be used and superscript $p$ indicates that predicted quantities are used to obtain the corrected quantities denoted by the superscript $c$. $\Delta x, \Delta y$ and $\Delta t$ are space and time intervals, respectively. $L x_{2}$ and $L y_{2}$ are like $L x_{1}$ and $L y_{1}$ except that a forward difference is used in the predictor step and a backward difference is used in the corrector step.

Although derivatives are discretized to first-order accuracy, the operator-splitting technique achieve second-order accuracy in space and time. The stability of the scheme can be determined by the Courant-Friedrichs-Lewy condition, which for the twodimensional case is:

$$
\Delta t \leq \frac{\Delta x \Delta y}{\sqrt{\Delta x^{2}+\Delta y^{2}}} \frac{C F L}{\left(\sqrt{v_{x}^{2}+v_{y}^{2}}+\sqrt{g h}\right)_{\max }}
$$

where $C F L$ is the Courant- Friedrichs-Lewy number which can take values up to 1 .

\section{Initial conditions}

The numerical model considers rain falling on initially dry soil bed. In terms of initial conditions this translates into flow depths, flow velocities and sediment concentrations all set equal to zero for all computational points. Also, it is possible that, after the rainfall event, the soil surface dries up again. This originates numerical complications that need to be solved using specific procedures. One is the surging of very shallow water depths, in which case velocities need a special treatment (Esteves et al., 2000). The other is the wetting/drying front that can originate computational negative water depths that need to be corrected for the next time step (Martins et al., 2017).

In the case of very shallow water depths, velocities need a special treatment because the motion of a very shallow flow is not correctly described by Eqs. (1-3). Also, unrealistically large values of the friction slope are computed when such water depths occur. Therefore, in this model, for water depths lower than $0.1 \mathrm{~mm}$, velocities were computed considering the kinematic approximation, as follows:

$$
v_{x}=\frac{1}{n} h^{\frac{2}{3}}\left|\frac{\partial Z}{\partial x}\right|^{\frac{1}{2}} \quad, \quad v_{y}=\frac{1}{n} h^{\frac{2}{3}}\left|\frac{\partial Z}{\partial y}\right|^{\frac{1}{2}}
$$

In the case of negative depths, the following procedure was implemented. Firstly, after each time step, the computational points were differentiated between having negative depths $\left(\eta_{i, j}=0\right)$ and having null or positive depths $\left(\eta_{i, j}=1\right)$. Secondly, whenever a point with a negative depth is identified $\left(\eta_{i, j}=0\right)$, the sum of the positive depths of the four closer adjacent neighbours is calculated $\left(h_{\text {sumi }}\right)$.

$$
h_{\text {sum }_{i, j}}=(\eta h)_{i+1, j}+(\eta h)_{i-1, j}+(\eta h)_{i, j+1}+(\eta h)_{i, j-1} \quad \text { if } \quad \eta_{i, j}=0
$$

Finally, if $h_{\text {sumi }, j}$ is greater than the absolute value of the negative depth of the respective point $\left(\left|h_{\text {negi,j }}\right|\right)$, the negative depth is set to zero and the positive depths of the four neighbours that contributed to $h_{s u m i, j}$ are reduced a fraction, as exemplified for the neighbour point $h_{i+1, j}$ :

$h_{i+1, j}=h_{i+1, j}-\frac{\left|h_{\text {neg }_{i, j}}\right| h_{i+1, j}}{h_{\text {sum }}, j}$ if $\quad \eta_{i, j}=0 \quad$ and $\quad \eta_{i+1, j} \quad$ and $\quad h_{\text {sum }},>\left|h_{n e g_{i, j}}\right|$

If $h_{\text {sumi }, j}<\left|h_{\text {negi,j }}\right|$ the positive depths of the next four closer adjacent neighbours (e.g. diagonal neighbours) are added to the sum and the process is repeated.

\section{Boundary conditions}

In the numerical model, the physical domain was represented as a square divided in a uniform grid with longitudinal and transversal slope in $x$ and $y$ directions, respectively. Each direction is represented with a closed boundary (i.e. solid wall limiting the flow) at the upper end and an open boundary (i.e. outlet) at the lower end. Geometry and boundary characteristics of the physical domain are better explained in the "METHODOLOGY" section.

Apart from the common elimination of the normal velocity component at the upper closed boundaries, an additional condition of zero tangential velocity at the wall has shown to improve the numerical solution (Garcia and Kahawita, 1986; Simões, 2006):

$$
\begin{array}{cc}
v_{x_{\mathrm{UB}, \mathrm{j}}}=0 & v_{y_{\mathrm{i}, \mathrm{UB}}}=0 \\
v_{x_{U B-1, j}}=-v_{x_{U B+1, j}} & , \quad v_{y_{\mathrm{i}, \mathrm{UB}-1}}=-v_{y_{\mathrm{i}, \mathrm{UB}+1}}
\end{array}
$$

where $(U B, j)$ and $(i, U B)$ represent the computational points at the upper closed boundaries in the $\mathrm{x}$ and $\mathrm{y}$ direction, respectively.

Since the flow was always supercritical, the lower open boundaries were considered free and no special treatment was necessary (Garcia and Kahawita, 1986; Simões, 2006). 